\title{
PATENTES SOBRE BIOMATERIALES DERIVADOS DEL CUERPO HUMANO: DERECHOS DE PROPIEDAD INDUSTRIAL V.S. DERECHO A LA SALUD EN MÉXICO
}

\author{
KAREN LIZETH GUTIÉRREZ AvALOS \\ Universidad Univer Colima \\ lizethgutierrezavalos@gmail.com
}

\section{CARLOS ERNESTO ARCUdia HERNÁNDEZ}

Universidad Autónoma San Luis de Potosí

carlos.arcudia@uaslp.mx

Fecha de recepción: 01/09/2020 - Fecha de aceptación: 01/02/2021

\begin{abstract}
RESUMEN: La concesión de patentes sobre biomateriales derivados del cuerpo humano plantea tensiones entre el derecho de propiedad industrial y el derecho a la salud. En el presente trabajo repasamos el derecho europeo de patentes como referente para interpretar la legislación mexicana en la materia. Y de otra parte, analizamos las implicaciones de concesión de biopatentes en el derecho a la salud en sus dos facetas: de acceso a los servicios de salud y de los parámetros éticos que se han de cumplir en investigaciones sobre salud en seres humanos. Por último analizamos solicitudes presentadas ante el Instituto Mexicano de la Propiedad Industrial y comprobaremos si se cumplen o no con los parámetros marcados por la legislación en materia de salud.
\end{abstract}

Palabras clave: patentes, biotecnología, salud, bioética, investigación.

ABSTRACT: Patents grants of biomaterials derived from the human body sets tension between the intellectual property law and the health rights. In this paper we re-examine the Patents European Law as a guide to interpreter the Mexican law in this subject. And, on the other hand we analyse the implications on patent grants in both aspects of health rights: in the access to the health services and in the ethics parameters that must be fulfilled in researches of human beings health. And finally, we analyse applications submitted to the Industrial Property Mexican Institute and verify if the parameters stated by the health legislation are or are not obeyed

Keywords: patens, biotechnology, health, bioethics, research.

SUMARIO: I. INTRODUCCIÓN - II. UNA APROXIMACIÓN A LA REGULACIÓN DE LAS PATENTES SOBRE BIOMATERIALES DERIVADOS DEL CUERPO HUMANO EN EL DERECHO EUROPEO - III. LAS PATENTES BIOTECNOLÓGICAS EN EL DERECHO MEXICANO - 1. Requisitos de patentabilidad con énfasis en biomateriales derivados del cuerpo humano - 2. Excepciones a la patentabilidad, con énfasis en biopatentes - IV. EL DERECHO A LA SALUD Y EL DERECHO A LA PROTECCIÓN DE LA SALUD - 1. El derecho a la protección de la salud en la constitución mexicana - 2. El derecho a la protección de la salud en la legislación mexicana - 3. Derecho a la protección de la salud, patentes y acceso a medicamentos - V. LINEAMIENTOS Y PRINCIPIOS BIOÉTICOS EN LA INVESTIGACIÓN CIENTÍFICA Y TECNOLÓGICA - 1. Ley general de salud -2 . Reglamento de la ley general de salud en materia de investigación para la salud -3 . Norma oficial mexicana nom-012-ssa3-2012, que establece los criterios para la ejecución de proyectos de investigación para la salud en seres humanos - 4. Norma oficial mexicana nom-257-ssa1-2014 en materia de medicamentos biotecnológicos - VI. ANÁLISIS DE LAS SOLICITUdES DE PATENTES SOBRE BIOMATERIALES DERIVADOS DEL CUERPO 
HUMANO PRESENTADAS ANTE EL INSTITUTO MEXICANO DE LA PROPIEDAD INDUSTRIAL - 1 . Solicitudes $\mathrm{mx} / \mathrm{a} / / 2007 / 003885$ y pa/a/2006/008360 del centro de investigaciones avanzadas -2 . Solicitud nl/a/2006/000035 del centro público de investigación instituto potosino de ciencia y tecnología - 3. Solicitudes mx/a/2008/012111 y $\mathrm{pa} / \mathrm{a} / 2006 / 007636$ del instituto mexicano del seguro social - VII. ConCLUSIONES - VIII. REFERENCIAS BIBLIOGRÁFICAS.

\section{INTRODUCCIÓN}

Desde sus orígenes, las patentes son monopolios temporales que se conceden a los inventores para promover la innovación. Este sistema, originado en la República de Venecia en el siglo XV, se adaptó perfectamente a las necesidades de invenciones sobre materia inerte. Es durante el siglo XX, que comienza la demanda por protección de innovaciones sobre materia viva.

En efecto, las primeras demandas de protección fueron sobre materia vegetal, producto de los desarrollos de la industria agrícola. En principio se saldó con la promulgación de leyes de protección específica para la industria de la obtención vegetal. El problema surge cuando, producto de las técnicas de biotecnología moderna — ADN recombinante — la innovación llega a tal grado que estamos en presencia de auténticas invenciones sobre materia viva vegetal o animal.

Las legislaciones de patentes trataron de contemplar estos supuestos y en Europa a partir de la promulgación de la Directiva 98/44 sobre Invenciones Biotecnológicas ${ }^{1}$ se hace una declaración general de patentabilidad de materia viva. El tema que nos ocupa, en el presente trabajo, son las patentes sobre materia viva de origen humano. Esto trae, además de un tema meramente de carácter técnico, un debate profundo sobre los derechos humanos afectados. En este trabajo haremos hincapié en el derecho a la salud.

La resignificación de los derechos humanos dentro del nuevo paradigma biotecnológico viene a consolidar su carácter progresivo con el que han quedado rebasados los conceptos generales que se les atribuían en un primer tiempo².

En esta tesitura, aunque es notable el beneficio de las aplicaciones biotecnológicas en la mejora de las condiciones de vida en la sociedad, se ha evidenciado una divergencia entre las personas que pueden acceder a los frutos de la ciencia y aquellas que no pueden beneficiarse de ella. En efecto, debido a la privatización de los servicios obtenidos por dichos procesos que en cierta medida, restringen el acceso a la población de escasos recursos quienes no pueden costear el servicio, situación que trae como consecuencia una limitación en la satisfacción parcial o total de sus derechos humanos ${ }^{3}$. Nosotros consideramos que la implementación de patentes sobre biomateriales derivados del cuerpo humano tiene efectos en el derecho a la salud.

\footnotetext{
${ }^{1}$ Directiva 98/44/CE del Parlamento Europeo y del Consejo de 6 de julio de 1998 relativa a la protección jurídica de las invenciones biotecnológicas.

2 PÉREZ REYES, C., Glosario de Términos Básicos de Derechos Humanos, CDHDF, México, 2005, p. 61. La progresividad de los derechos humanos es entendida como "[...] la expansión de la protección de los derechos humanos en forma paulatina y continua que puede ser expresada como el reconocimiento e inserción de nuevos derechos en la leyes o en la expedición de normas que permitan el desarrollo de los derechos humanos[...] parte del reconocimiento del hecho de que la plena efectividad de los derechos económicos, sociales y culturales no podrán lograrse en un breve periodo de tiempo"

${ }^{3}$ BOYLE, J., "Las ideas cercadas: el Confinamiento y la Desaparición del Dominio Público", en VILLARREAL PADILLA, J., ¿Un mundo patentado? La privatización de la vida y el conocimiento, Bellas Artes, El Salvador, 2005, p. 39. "Esta situación tiene comunes denominadores con el movimiento inglés de los cercados del siglo XV-XIX, destinado a la apropiación de tierras comunales para propiedad privada, lo que generaron devastadores costos en el segmento más desfavorecido de la sociedad, una polarización entre los ricos y los pobres, en ese sentido, hoy en día
} 
Así las cosas, a medida que aumenta el uso de las aplicaciones biotecnológicas, mayor es la exigencia de la sociedad moderna por que sean satisfechos sus derechos humanos, no solo por aspirar a los beneficios de esta ciencia, sino por la necesidad de verlos reflejados en la materialización de mejores condiciones de vida, mejoras en el acceso a condiciones óptimas de salud, derecho al agua, a una alimentación nutritiva, igualdad de oportunidades, entre otras prerrogativas igualmente importantes. Estas condiciones se convierten en un efecto en cadena que culmina con la privatización de servicios básicos que, además de ser una limitante en el cumplimiento de los derechos humanos de los sectores vulnerables, contribuye a fraguar un nuevo estado de desvalorización del individuo y la pérdida de su dignidad humana, situación que es justificada por el Estado en la obtención de un beneficio social a largo plazo ${ }^{4}$.

En el presente trabajo nos planteamos hacer un repaso de los principales instrumentos legales que protegen, tanto las patentes sobre biomateriales derivados del cuerpo humano, como el derecho a la salud. En cuanto a este último, lo desdoblaremos en el acceso a los tratamientos con medicina genética y en las consideraciones éticas sobre la investigación biomédica para producir nuevos medicamentos basados en la genética humana.

Comenzaremos nuestro análisis del derecho de patentes aplicado al cuerpo humano con el derecho europeo. Y es que el ordenamiento jurídico nacional mexicano posee una similitud muy grande con el derecho europeo. En concreto nuestra Ley de Propiedad Industrial ${ }^{5}$ (LPI) sigue la misma reglamentación del Convenio de la Patente Europea $(\mathrm{CPE})^{6}$. Por ende, las pautas de aplicación de éste contenidas en la Directiva 98/44 sobre Invenciones Biotecnológicas pueden servir de criterio de referencia para interpretar y aplicar la legislación mexicana a solicitudes de patentes biotecnológicas.

\section{UNA APROXIMACIÓN A LA REGULACIÓN DE LAS PATENTES SOBRE BIOMATERIALES DERIVADOS DEL CUERPO HUMANO EN EL DERECHO EUROPEO}

Hasta hace relativamente poco tiempo las invenciones sobre materia viva humana eran casi un producto de la ciencia ficción. En nuestros días son una realidad tangible y la demanda de protección de las mismas — vía patente- es un hecho innegable.

La suposición de que toda la materia que habita en el cuerpo humano es materia viva, pudiera inducir al intérprete de la ley a conclusiones equivocadas en situaciones en las que está de por medio la aplicación de la norma que prohíbe el otorgamiento de patentes que involucran el cuerpo humano, y particularmente, las partes vivas que lo componen ${ }^{7}$.

En esta tesitura, el sistema europeo de patentes representa un esfuerzo por la uniformidad de criterios para obtener la protección patentaria. En 1973 se consolida con el CPE. Este tratado internacional - también conocido como Convenio de Múnich- crea a la Organización Europea de Patentes, cuyo órgano ejecutivo recae en la Oficina Europea de

se vive un cercamiento pero sobre bienes intangibles, la privatización de datos, secuencias genéticas, posibilitados por el Estado, frustrando el beneficio público y la riqueza de unos cuantos[...]".

4 DARIO BERGEL, S., "El vínculo de la genética con los derechos humanos", en PENCHASZADEH, V. B., Genética y derechos humanos, encuentros y desencuentros, Paidós, Buenos Aires, 2012, p. 57.

${ }^{5}$ Ley de la Propiedad Industrial, publicada en el Diario Oficial de la Federación el 27 junio de 1991.

${ }^{6}$ Convenio de Múnich sobre Concesión de Patentes Europeas, de 5 de octubre de 1973.

${ }^{7}$ RANGEL ORTÍZ, H., "Las invenciones que involucran materia viva en el Derecho mexicano", Estudios de derecho de autor y propiedad industrial homenaje al Licenciado José Luis Caballero Cárdenas, OMPI, México, 2015, p. 281. 
Patentes $(\mathrm{OEP})^{8}$; conjuntamente forman parte de un sistema centralizado de concesión simultánea para los 38 países confederados, resalta por la libre elección del ámbito territorial de protección, ya que permite que las patentes puedan tener cobertura en el país contratante o en varios de ellos según la elección del o los solicitantes?.

Los requisitos de patentabilidad —incluyendo a las invenciones biotecnológicas-, se regulan en el artículo 52 del CPE. En efecto, toda aquella invención novedosa, que demuestre actividad inventiva y tenga aplicación industrial, podrá acceder a una patente. Las excepciones de patentabilidad están normadas en el artículo 53 del CPE bajo las restricciones para invenciones que contraríen al orden público, las buenas costumbres, las variedades vegetales $o$ las razas animales con determinadas particularidades, tratamientos quirúrgicos, métodos de diagnóstico aplicados al cuerpo humano.

Estos criterios de patentabilidad y sus excepciones se han ido adaptando a las necesidades de la industria biotecnológica. El texto original del CPE no contemplaba lineamiento alguno en materia biotecnológica debido a su reciente impulso. No obstante, la doctrina precisa que el CPE se ocupa de normar el procedimiento y las Directivas de la regulación sobre las condiciones de la patentabilidad. Para efectos del objeto de la investigación únicamente abordaremos la Directiva 98/44 relativa a la Protección Jurídica de las Invenciones Biotecnológicas.

La Directiva 98/44 es una de las disposiciones más integrales respecto a de patentabilidad sobre el cuerpo humano. Este instrumento consta de 56 considerandos y 18 artículos. Así pues la directiva refiere como patentables inventos aun cuando éstos contengan materia biológica o impliquen un procedimiento de producción, transformación o utilización de materia viva ${ }^{10}$, igualmente los elementos aislados del entorno natural ${ }^{11}$.

Las excepciones aparecen en el artículo $4^{\circ}$ de la Directiva 98/44; de manera general comparten características con el CPE y demás ordenamientos, la diferencia es la precisión de la Directiva. Ahora bien, los artículos 5 y 6 de la Directiva 98/44 desarrollan las excepciones a la patentabilidad. En efecto, en el artículo 5 de la Directiva se enlistan el cuerpo humano, los elementos aislados del cuerpo humano y las secuencias parciales de genes humanos. En el artículo 6 se regula la exclusión de invenciones contra la moralidad y el orden público en general (apartado 1); y algunos casos de invenciones sobre materia humana en particular $(\text { apartado } 2)^{12}$.

${ }^{8}$ Convenio de Múnich sobre la Patente Europa, op. cit.

${ }^{9}$ Convenio de Múnich sobre la Patente Europa, op. cit.

${ }^{10}$ Esta disposición es uno de los puntos clave fijado en los considerandos 20 y 21 de la Directiva; en ellos se refiere explícitamente a la no exclusión de patentabilidad del cuerpo humano bajo características específicas señaladas en el cuerpo normativo. OMPI/GRTKF/1C/1/8 ANEXO I, DIRECTIVA 98/44/CE, 22 de agosto de 2020. Disponible en http://www.wipo.int/edocs/mdocs/tk/es/wipo grtkf ic 1/wipo grtkf ic 1 8-annex1.pdf

${ }^{11}$ Artículo 3 de la Directiva 98/44/CE de invenciones biotecnológicas.

12 Artículo 5 de la Directiva 98/44 CE de invenciones biotecnológicas: "1. El cuerpo humano en los diferentes estadios de su constitución y de su desarrollo, así como el simple descubrimiento de uno de sus elementos, incluida la secuencia o la secuencia parcial de un gen, no podrán constituir invenciones patentables.

2. Un elemento aislado del cuerpo humano u obtenido de otro modo mediante un procedimiento técnico, incluida la secuencia o la secuencia parcial de un gen, podrá considerarse como una invención patentable, aun en el caso de que la estructura de dicho elemento sea idéntica a la de un elemento natural.

3. La aplicación industrial de una secuencia o de una secuencia parcial de un gen deberá figurar explícitamente en la solicitud de patente".

Artículo 6 de la Directiva 98/44 CE de invenciones biotecnológicas: “1. Quedarán excluidas de la patentabilidad las invenciones cuya explotación comercial sean contrarias al orden público o a la moralidad, no pudiéndose considerar 
Se debe tener en cuenta que la Directiva 98/44 no crea una patente europea, ni regula la protección que despliega la concesión patentaria; tampoco regula la investigación biotecnológica ni su aplicación; sino que determina las invenciones referentes a la materia viva que pueden ser patentadas. Ejemplo de ello es la exclusión de patentabilidad de invención cuando la información técnica de una solicitud requiera destrucción previa de embriones como materia prima.

Estas precisiones nacen de la necesidad de regular la falta de especificidad conceptual en materia de biotecnología, pues las patentes en este ámbito no solo requieren elementos de novedad, actividad inventiva y aplicación industrial, sino la justificación de dichos elementos en la materia viva, secuencias genéticas parciales o totales que se pretende patentar ${ }^{13}$. Es decir, lo patentable deberá acreditar enseñanzas de carácter técnico logrado por intervención humana. En ese sentido una secuencia de ADN simple sin estas características no podría ser patentada, de ahí su complejidad.

En un trabajo anterior ${ }^{14}$ se refirió que la falta de especificidad tanto del concepto de invención en el sistema europeo, términos de variedades vegetales y animales, así como procedimientos esencialmente biológicos ha dado lugar a nuevas interpretaciones doctrinales sobre biotecnología y ciencias no contempladas al momento de creación del Convenio, con lo cual se impulsaron criterios específicos. Tal es el caso de la Directiva 98/44 para patentes biotecnológicas.

Como hemos observado es evidente la preocupación de los sistemas patentarios de homologar lo respectivo a la concesión de patentes de material biológico del cuerpo humano. En este sentido, el CPE se vio complementado con el desarrollo legal de la Directiva 98/44 sobre invenciones biotecnológicas. Sin duda alguna se establecen pautas que dan certidumbre.

\section{CARACTERIZACIÓN JURÍDICA DEL LA MAQUETACIÓN Y DE OTRAS COSAS RELACIONADAS CON EL TEMA}

México es uno de los tres principales países proveedores de biotecnología en productos de ciencia de la vida para Estados Unidos ${ }^{15}$. Por ende, el marco jurídico para la concesión patentaria sobre biotecnología - específicamente sobre material biológico derivado del cuerpo - requiere exactitud sobre los parámetros referentes a materia viva, de tal suerte que la legislación de propiedad industrial no impacte negativamente al ámbito de los derechos humanos.

como tal la explotación de una invención por el mero hecho de que esté prohibida por una disposición legal o reglamentaria.

2. En virtud de lo dispuesto en el apartado 1, se considerarán no patentables, en particular:

a) los procedimientos de clonación de seres humanos;

b) los procedimientos de modificación de la identidad genética germinal del ser humano;

c) las utilizaciones de embriones humanos con fines industriales o comerciales;

d) los procedimientos de modificación de la identidad genética de los animales que supongan para estos sufrimientos sin utilidad médica sustancial para el hombre o el animal, y los animales resultantes de tales procedimientos".

${ }^{13}$ Considerando núm. 22 de la Directiva 98/44/CE de invenciones biotecnológicas.

${ }^{14}$ ARCUDIA HERNÁNDEZ, C., "Patentes sobre invenciones biotecnológicas: criterios legales y jurisprudenciales europeos y su aplicabilidad en el derecho mexicano", Revista Entreciencias, Diálogos en la sociedad del conocimiento, núm. 7, 2015, pp.167-182.

15 IZQUIERDO TOLOSA, A. y PÉREZ ZAZUETA, G., La Biotecnología en México, Secretaría de Economía, México, 2014, p. 14. 
Con la entrada en vigor de la Ley de la Propiedad Industrial (LPI) en 1991 creció exponencialmente la protección de la propiedad industrial. En efecto, según datos de la OMPI estiman que el número de solicitudes para obtener patentes en este rubro ha crecido en una tasa promedio anual de 9\% en un periodo de catorce años, de hecho de 1998 a 2012 se registraron 209,442 solicitudes de patentes de las cuales $14.39 \%$ se relacionan con la tecnología médica y farmacéutica ${ }^{16}$.

\section{Requisitos de patentabilidad con énfasis en biomateriales derivados del cuerpo humano}

En el ordenamiento mexicano lo relativo a las patentes de invención está regulado en el Capítulo II de la LPI. Hemos de resaltar la omisión de un concepto legal de patente y de una declaración expresa sobre la patentabilidad de invenciones biotecnológicas (que sí contiene la Directiva 98/44 en Europa). La LPI se limita a establecer precisiones sobre lo que es considerado como invención, definida como "toda creación humana que permita transformar la materia o la energía que existe en la naturaleza, para su aprovechamiento por el hombre y satisfacer sus necesidades concretas" ${ }^{\prime 17}$.

Las creaciones humanas serán patentables si cumplen con los requisitos de patentabilidad regulados en el artículo 16 de la LPI. Según esta norma serán patentables aquellas invenciones nuevas, resultado de una actividad inventiva y que sean susceptibles de aplicación industrial ${ }^{18}$, elementos compartidos con el sistema de propiedad industrial europeo para la concesión patentaria.

Es necesario hacer una precisión sobre la última frase del primer párrafo del artículo 16 de la LPI que requiere que las invenciones deberán ceñirse a los términos de la ley. Esta acotación hace referencia a los requisitos de novedad establecidos en el artículo 17 y 18 de la LPI ${ }^{19}$, así como a las excepciones a la patentabilidad que se observarán en el siguiente apartado.

La doctrina mexicana señala que el elemento de aplicación industrial debe ser factible, realizable, materializarse en la práctica y no estribar en una mera especulación que se traduzca en ventaja para la industria ${ }^{20}$. Nuestro país tiene las posibilidades técnicas, económicas y humanas para realizar innovaciones en el campo biotecnológico, específicamente en relación a patentes biológicas, reflejo de ello es la recepción de activos inmateriales mexicanos en países desarrollados como Estados Unidos. Esta situación es un claro ejemplo de la verificación de los criterios de actividad inventiva, novedad y aplicación industrial en territorio mexicano ${ }^{21}$.

De hecho el catálogo de patentes de invenciones del Instituto Mexicano de Propiedad Industrial, IMPI, publicadas en el sistema de información de la Gaceta de la Propiedad

\footnotetext{
${ }^{16}$ IZQUIERDO TOLOSA, A., La Biotecnología en México, op. cit., p. 14.

${ }^{17}$ Artículo 15 de la L.P.I.

${ }^{18}$ Artículo 16 de la Ley de Propiedad Industrial, L.P.I.

${ }^{19} \mathrm{El}$ artículo 17 de la L.P.I. establece que una patente será determinada como nueva y resultado de una actividad inventiva, dependiendo la fecha de presentación de la solicitud de la patente, dentro del análisis se incluirán todas las solicitudes de patente que se encuentren en trámite respecto al mismo invento; por otro lado el artículo 18 de la L.P.I. establece la temporalidad sobre la cual una patente podrá considerarse como nueva en caso de divulgación.

20 RANGEL MEDINA, D., Derecho Intelectual, México, 1998, p. 25. Disponible en https://archivos.juridicas.unam.mx/www/bjv/libros/4/1912/5.pdf

${ }^{21}$ IZQUIERDO TOLOSA, A., La Biotecnología en México, op. cit., p. 14.
} 
Industrial del IMPI, arroja que del periodo de 1991 al 2009²2, en el territorio mexicano, fueron solicitadas patentes sobre biomateriales derivados del cuerpo humano; lo que corrobora que México es un país activo en la producción de ciencia, con intereses de adquirir protección jurídica para sus invenciones. Abordaremos algunas solicitudes con posterioridad.

$\mathrm{Al}$ respecto Trens Flores refiere que la falta de pautas en los requisitos para la obtención de patentes derivadas del cuerpo, ha generado una zona gris en el ámbito jurídico por la incertidumbre sobre los criterios tomados por el Instituto Mexicano de Propiedad Intelectual, IMPI $^{23}$; en consecuencia la interpretación de los elementos positivos generales de patentabilidad dictados en la LPI invita a cuestionarse, ¿es patentable la materia biológica humana en México? ¿Cuáles son los parámetros para su concesión? ¿Son procedimentales o atienden criterios de protección a derechos humanos? Para contestar las interrogantes comenzaremos por precisar en las excepciones nacionales de patentabilidad.

\section{Excepciones a la patentabilidad, con énfasis en biopatentes}

Las exclusiones generales sobre lo que no será considerado como invención y por ende no podrá ser materia patentable son precisadas en el artículo 19 de la LPI. El numeral refiere que no serán objetos susceptibles de patentabilidad los principios teóricos o científicos, los descubrimientos consistentes en dar a conocer algo existente en la naturaleza, esquemas, planes reglas para actos, juegos, teorías matemáticas, programas informáticos bajo ciertas características, formas de presentación de información, creaciones estéticas, obras artísticas o literarias y los métodos de tratamiento quirúrgico, terapéutico o de diagnóstico aplicables al cuerpo humano y los relativos a animales; tampoco se podrán patentar invenciones derivadas de mezclas de productos conocidos, bajo condiciones específicas.

En cuanto a las excepciones para el material biológico, aparecen como una referencia en el artículo 16 de la LPI que a la letra dice: serán patentables las invenciones que sean nuevas, resultado de una actividad inventiva y susceptibles de aplicación industrial [...] excepto, (I) los procesos esencialmente biológicos para la producción, reproducción y propagación de plantas y animales; (II) el material biológico y genético tal y como se encuentra en la naturaleza; (III) las razas animales; (IV) el cuerpo humano y las partes vivas que lo componen y (V) las variedades vegetales. Regulación similar al CPE, que hemos analizado en un apartado anterior.

Las excepciones sobre materia viva conllevan a determinar que el límite de la patentabilidad fijado por la LPI radica en analizar que el objeto a patentar no conste de materia viva en su estado puro, es decir, su consistencia debe alejarse de la esencia natural del elemento manipulado; de tal suerte que se puede patentar material biológico humano, animal y vegetal siempre y cuando éstos sean obtenidos por procesos de ingeniería genética o ciencias derivadas, además de justificar aplicación industrial para el producto ${ }^{24}$.

Esta es la razón por la cual la legislación mexicana permite el patentamiento de genes, células, enzimas, proteínas, entre otros componentes obtenidos del cuerpo humano, siempre y cuando medie aislamiento o modificación del estado natural del elemento, de ahí que podamos

\footnotetext{
22 UNIVERSIDAD NACIONAL AUTÓNOMA DE MÉXICO, Catálogo de patentes de Invención Solicitadas: Publicadas en el Sistema de Información de la Gaceta de la Propiedad Industrial del Instituto Mexicano de la Propiedad Industrial 1991-2009. Disponible en http://dgei.unam.mx/patentes/catalogo general.pdf

${ }^{23}$ TRENS FLORES, E. y MORALES LECHUGA, V., “A propósito de la patente de los genes”, Revista Facultad de Medicina UNAM, núm. 6, 2003, p. 226.

${ }^{24}$ Ibid., p. 227.
} 
observar solicitudes patentarias bajo estos rubros ${ }^{25}$. En este sentido, podemos ver que existe una total convergencia con las pautas de patentabilidad de la Directiva 98/44 sobre Invenciones Biotecnológicas.

Así pues, tanto en México como en los países periféricos, la tendencia actual estriba en la manipulación de los componentes del cuerpo humano por medio de procesos biotecnológicos para la obtención de productos, servicios comercializables o conocimiento, tal es el caso de las investigaciones realizadas en células humanas; paralelamente a su estudio subsiste una marcada posición en contra de la manipulación celular y su patentamiento. El principal argumento se funda en la negativa de catalogarlas como invenciones patentables cuando son consideradas como una simple manipulación técnica ${ }^{26}$, conflicto que se agudiza frente a una legislación patentaría imprecisa sobre los requisitos y excepciones cuando de biopatentes se trata.

Una vez analizados los requisitos y excepciones para la concesión de patentes nacionales, con énfasis en aquellas otorgadas sobre material biológico derivado del cuerpo humano, corresponde indagar en los ordenamientos sobre el derecho a la salud relacionado con las patentes sobre biomateriales derivados del cuerpo humano.

\section{EL DERECHO A LA SALUd Y EL DERECHO A LA PROTECCIÓN DE LA SALUD}

La Organización Mundial de la Salud (OMS) ha definido a la salud como un estado integral de bienestar físico, mental, social y no solamente como la ausencia de afecciones o enfermedades ${ }^{27}$. Por ende, su protección trae consigo actos de hacer y no hacer por parte de una entidad pública en aras de garantizar un estado de completo bienestar, de acuerdo a los términos referidos ${ }^{28}$.

Por lo que el derecho de protección a la salud se ha definido como el medio para hacer efectivo el derecho humano a la salud tutelado por una norma fundamental, a entenderse como:

[...] el sistema de normas jurídicas de derecho social, que tiene por objeto, regular los mecanismos para lograr la protección de la salud como bien supremo del

\footnotetext{
${ }^{25}$ RANGEL ORTÍZ, H., "Las invenciones que involucran materia viva en el Derecho mexicano", op. cit., pp. 284285. Todo indica que a los ojos del IMPI se considera que existe una invención patentable cuando el solicitante no se ha limitado a presentar material genético aislado y purificado, sino además modificado. La exclusión de la protección del cuerpo humano y las partes vivas que lo componen se refiere únicamente a las partes del cuerpo humano como tales, pues la norma no tiene aplicación a situaciones distintas de las ahí previstas. Es el caso de partes del cuerpo humano representadas por líneas celulares humanas, aisladas e involucradas en una invención biotecnológica, respecto de las cuales no ha existido inconveniente para ser incluidas en las reivindicaciones de una patente mexicana..

26 TRENS FLORES, E y MORALES LECHUGA, V., “A propósito de la patente de los genes”, op. cit., pp. 226-228.

27 ORGANIZACIÓN MUNDIAL DE LA SALUD, ¿Cómo define la OMS a la salud?. Disponible en http://www.who.int/suggestions/faq/es/

${ }^{28}$ El Alto Comisionado para los Derechos Humanos de Naciones Unidas se ha pronunciado a la protección de la salud como un derecho derivado del derecho a la salud consistente en la obligación de generar un sistema de protección a la salud que brinde a todas igualdades de oportunidades para disfrutar del más alto nivel posible de salud. Véase OFICINA DEL ALTO COMISIONADO DE LAS NACIONES UNIDAS PARA LOS DERECHOS HUMANOS, El derecho a la Salud, Folleto informativo, núm. 31, Naciones Unidas, Ginebra, 2008, p. 4. Disponible en http://www.ohchr.org/Documents/Publications/Factsheet31sp.pdf
} 
hombre, a través de la delimitación del campo de la actividad gubernamental, social e individual, siendo esta un elemento de justicia social ${ }^{29}$.

Para la OMS la protección a la salud tiene como objetivo propiciar el derecho al grado máximo de salud que se pueda lograr a través de la exigencia de criterios sociales, que conlleven a su materialización para todas las personas sin distinción alguna; entre estos criterios se encuentra la disponibilidad de los servicios de salud, condiciones seguras en los ambientes laborales, vivienda digna, alimentación nutritiva, solo por mencionar algunos rubros ${ }^{30}$.

Esta postura es compartida por Alejandro Ramírez López, además refiere que el derecho a la salud y su protección debe ser un derecho progresivo al incluir concepciones nacientes de contextos actuales para lograr el equilibrio del medio ambiente, un mejor acceso a condiciones de igualdad en los servicios sanitarios, acceso a fármacos desarrollados, intervenciones quirúrgicas entre otros; lo que para él es una expresión directa de justicia ${ }^{31}$.

En sentido contrario, para Maurice Cranston el derecho a la protección a la salud debe ser comprendido como "el derecho del que gozan las personas, o las poblaciones a recibir servicios otorgados por los profesionales de la salud, con exclusividad" ${ }^{32}$, es decir, desde una concepción amplia este derecho es una titularidad específica, una pequeña muestra de todo un universo de aspectos relacionados con el derecho a la salud, lo que para él implica la imposibilidad de lograr estándares de salud en igualdad de condiciones, así como su protección.

Para efectos de este trabajo, tomaremos el criterio de Buchanan y Hessler citado por Cantoral Domínguez ${ }^{33}$, cuya idea de protección a la salud funda sus raíces en la necesidad humana básica, indispensable para la supervivencia, como derecho humano: "todas las personas del mundo, independientemente de su nacionalidad, cultura, país de ciudadanía o alguna otra característica distintiva, pueden demandar la titularidad moral a tener ciertos servicios médicos y a recibir servicios de salud pública".

En consideración a lo anterior y atendiendo a los principios rectores de los derechos humanos, sería un error considerar al derecho humano a la salud y a su protección como derechos aislados, pues están correlacionados a otros de igual importancia. Por ende, su constitución como un derecho humano complejo trae aparejada obligaciones explicitas en ordenamientos jurídicos, como se observará en las siguientes líneas.

\section{El derecho a la protección de la salud en la constitución mexicana}

El artículo $4^{\circ}$ de la Constitución Política de los Estados Unidos Mexicanos (CPEUM) establece que toda persona tiene derecho a la protección de la salud. Debido a la ausencia de definición conceptual de este derecho y sus alcances en la Constitución, la Suprema Corte de Justicia de la Nación (SCJN) ha realizado interpretaciones para precisar su contenido.

\footnotetext{
${ }^{29}$ CANTORAL DOMínGUEZ, K., Derecho a la protección de datos personales de la salud, Novum, México, 2012, p. 107.

30 ORGANIZACIÓN MUNDIAL DE LA SALUD, Salud y derechos humanos: Datos y cifras. Disponible en http://www.who.int/mediacentre/factsheets/fs323/es/

${ }^{31}$ RAMÍREZ LÓPEZ, A., Derecho a la salud, UNAM, México, 2003, p.16.

32 DIETERLEN, P., "La Protección a la salud como un mínimo decente y como un derecho básico", en Justicia distributiva y salud, Tópicos, México, 2015, p. 166.

${ }^{33}$ CANTORAL DOMÍNGUEZ, K., Derecho a la protección de datos personales de la salud op. cit. p. 89.
} 
Destaca el pronunciamiento para la efectiva protección al derecho a la salud; para la SCJN, el Estado tiene la obligación de crear instituciones que procuren la salud; y además, formular programas sociales, dar atención individualizada, de calidad, seguimiento oportuno a cada persona de manera igualitaria, y sin distinción alguna — principios de universalidad, equidad y calidad- También establece la prohibición a cualquier empresa o particular de realizar acciones que puedan atentar contra el derecho a la protección a la salud de cada individuo ${ }^{34}$.

La universalidad del derecho en comento deriva de su esencia como derecho humano reconocido por instrumentos de carácter internacional, pero también en vía directa por el texto constitucional, ya que designa su atribución y perfeccionamiento en el derecho interno para beneficio de todas las personas; mientras que por equidad en protección a la salud, los servicios de salud tienen un carácter de servicio público y por ende deben ser financiados por el Estado , evitando con ello la discriminación en el acceso y la redistribución de los ingresos públicos ${ }^{35}$.

En cuanto al elemento de calidad en el servicio sanitario es interpretado como:

“...un requisito tanto de existencia mínima del sistema sanitario comprendido globalmente, como un elemento para alcanzar un mínimo de igualdad entre quienes acceden a los servicios públicos de salud y de quienes lo hacen a servicios privados" 36 .

Para la materialización de los derechos económicos y sociales, como el caso del derecho en comento, el Comité de Derechos Económicos, Sociales y Culturales de la Organización de Naciones Unidas, emitió criterio intitulado "Evaluación de la Obligación de Adoptar Medidas hasta el Máximo de los Recursos de que Disponga" "De conformidad con un Protocolo facultativo del Pacto", en lo que interesa se señala que "el derecho a la salud, entraña libertades y derechos, de los derechos destaca un sistema de protección de la salud que brinde a las personas oportunidades iguales para disfrutar del más alto nivel de salud" ${ }^{37}$. Por otro lado, refiere que el Estado al no adoptar medidas adecuadas para dar cumplimiento al derecho universal al acceso sanitario, infringiría con sus obligaciones legales suscritas por los pactos internacionales.

\section{El derecho a la protección de la salud en la legislación mexicana}

Las acciones específicas para el cumplimiento del derecho a la protección a la salud son desglosadas en la Ley General de Salud ${ }^{38}$ (LGS), considerada por la SCJN como reglamentaria del artículo $4^{\circ}$ constitucional. Ésta se encarga de definir los propósitos del derecho a la salud, al señalar expresamente que su finalidad es asegurar lo siguiente:

- El bienestar físico y mental del hombre para contribuir al ejercicio pleno de sus capacidades;

\footnotetext{
${ }^{34}$ SCJN, del Juicio de Amparo en Revisión 378/2014, foja 116.

${ }^{35}$ CARBONELL, J. y CARBONELL, M., El derecho a la salud, una propuesta para México, UNAM, México, 2013, p. 4. Disponible en https://archivos.juridicas.unam.mx/www/bjv/libros/7/3274/3.pdf

${ }^{36}$ CANTORAL DOMÍNGUEZ, K., Derecho a la protección de datos personales de la salud, op. cit., p. 114.

37 COMITÉ DE DERECHOS ECONÓMICOS, SOCIALES Y CULTURALES DE LAS NACIONES UNIDAS, Evaluación de la Obligación de Adoptar Medidas hasta el "Máximo de los Recursos de que Disponga" de Conformidad con un Protocolo Facultativo del Pacto, E/C.12/2007/1, 21 de septiembre de 2007. Disponible en http://undocs.org/sp/E/C.12/2007/1

${ }^{38}$ Ley General de Salud, publicada en el Diario Oficial de la Federación el 7 de febrero de 1984
} 
- La prolongación y el mejoramiento de la calidad de la vida humana;

- La protección y el acrecentamiento de los valores que coadyuven a la creación y conservación y disfrute de las condiciones de salud que contribuyan al desarrollo social;

- La extensión de actitudes solidarias y responsables de la población en la preservación, conservación, mejoramiento y restauración de la salud;

- El disfrute de los servicios de salud y de la asistencia social que satisfagan eficaz y oportunamente las necesidades de la población;

- El conocimiento para el adecuado aprovechamiento y utilización de los servicios de salud; y

- El desarrollo de la enseñanza y la investigación científica y tecnológica para la salud $^{39}$.

El artículo 77 Bis de la LGS dispone que todo mexicano tiene derecho a ser incorporado a un sistema de protección social en salud, como el mecanismo por el cual el Estado garantizará su acceso efectivo, oportuno y de calidad a los servicios farmacéuticos y hospitalarios para el mejoramiento de la salud, bajo criterios de eficacia, costo, efectividad y adheridos a normas éticas profesionales

Así pues, los servicios en materia de salud forman parte de los objetivos del Sistema Nacional de Asistencia Social como estructura adjetiva de la LGS ${ }^{40}$. El esquema de atención se divide en subsistemas, que ofrecen distintos niveles de atención, costos, y diversos resultados para el alcance óptimo de salud; la categorización de personas está determinada por su condición laboral ${ }^{41}$. Si bien el estudio de la Organización para la Cooperación y Desarrollo Económico (OCDE) del año 2016 arrojó que la protección sanitaria se amplió durante los diez años anteriores a la emisión del informe, refiere que existen varios problemas en el sistema sanitario mexicano ${ }^{42}$. Uno de los principales es la disparidad de subsistemas y su inequidad, ya que la afiliación a determinado sistema de salud no atiende a la necesidad real de la persona sino se atribuye según al tipo de empleo ${ }^{43}$.

Por otro lado, las normas éticas profesionales son parte de los criterios fundamentales para la operatividad del Reglamento de la Ley General de Salud en Materia de Prestación de Servicios de Atención Médica ${ }^{44}$. De ellas se desprende que la atención médica en México será otorgada conforme los principios científicos y éticos que orientan la práctica médica bajo

\footnotetext{
${ }^{39}$ Fracciones I a VII del artículo 2 de la LGS.

${ }^{40}$ El Reglamento de la Ley General de Salud en Materia de Prestación de Servicios de Atención Médica, que deriva de la LGS, además de tener como objetivo promover de forma administrativa el cumplimiento de la LGS, considera a la Secretaría de Salud como la responsable del control de prestación de servicios de atención médica a nivel nacional.

${ }^{41}$ En México los subsistemas de salud corresponden al Instituto Mexicano del Seguro Social (IMSS), Seguro Popular Instituto de Seguridad y Servicios Sociales para los Trabajadores del Estado (ISSSTE), Secretaría de Marina, Secretaría de la Defensa Nacional y PEMEX, cuyos esquemas de afiliación dependerán de la categorización laboral.

42 ORGANIZACIÓN PARA LA COOPERACIÓN Y EL DESARROLLO ECONÓMICOS (OCDE), Estudios Ejecutivos de la OCDE sobre los Sistemas de Salud: México, Resumen Ejecutivo, Diagnóstico y Recomendaciones, OECD, 2016, p. 3. Disponible en http://www.inep.org/images/2017/2017-pdf/2016-OECD-Reviews-of-HealthSystems-Mexico.pdf

${ }^{43}$ Ibid., p. 8. El informe de la OCDE ha concluido que la existencia de subsistemas sanitarios genera un sistema nacional fragmentado con problemas de acceso y calidad de servicio, lo cual contraviene a la estructura teórica del derecho humano a la protección a la salud.

${ }^{44}$ Artículo 9 del Reglamento de la Ley General de Salud en Materia de Prestación de Servicios de Atención Médica.
} 
lineamientos específicos en materia de salud denominadas Normas Oficiales Mexicanas en materia de salud ${ }^{45}$.

Como se observa, el derecho humano a la salud es parte fundamental de la estructura jurídica suprema del Estado Mexicano, por lo tanto lleva implícita su garantía de cumplimiento directo, de lo contrario si el sistema de derechos humanos no ofrece a sus titulares su pronta materialización frente a los sujetos obligados, entonces no se le podría catalogar como un verdadero derecho ${ }^{46}$.

La reflexión sobre su efectiva garantía, nos hace cuestionarnos sobre el papel del derecho humano a la salud visto a la luz del avance biomédico y los conflictos jurídicos/éticos/morales que de él se derivan. Así pues conviene profundizar en el derecho a la protección a la salud en las sociedades contemporáneas.

\section{Derecho a la protección de la salud, patentes y acceso a los medicamentos}

Para Elizondo Mayer-Serra el derecho a la protección de la salud dentro de las sociedades contemporáneas, es un bien que los seres humanos esperan sea racionalizado de acuerdo a la necesidad de las personas, como un criterio de distribución justo, independientemente de su capacidad de pago ${ }^{47}$. Esta situación se torna crítica debido a la concepción materialista, de acumulación de capital y con fines utilitaristas que ha primado durante las últimas décadas, a pesar de que el derecho a la protección de salud es contemplado por los ordenamientos internos nacionales e instancias internacionales.

En efecto, hay un evidente sesgo en las condiciones de acceso que desembocan en acciones de discriminación, con lo que se amplían las diferencias estructurales en el acceso a los recursos y a las oportunidades en salud a las que personas tienen derecho, aunque en los ordenamientos nacionales e internacionales sea concebido como universal ${ }^{48}$. Y con universal nos referimos al reconocimiento de cada ser humano como sujetos de derechos, independientemente de sus características sociales. Es evidente que en efecto existe ese reconocimiento, pero no basta con eso, se tiene que verificar su acceso equitativo, de lo contrario se generaría desigualdad social.

En esta tesitura, los servicios médicos que otorga el Estado son asequibles en diversos países por el simple hecho de ser ciudadanos. Ahora bien, en el caso mexicano, la precariedad en el servicio origina que exista un doble sistema de salud, es decir, un sistema de salud público que subsiste a la par del sistema de salud privado, del cual la sociedad se enfrenta ante dos panoramas, el primero correspondiente a un sistema de salud abierto a la población, que opera

\footnotetext{
45 SECRETARÍA DE SALUD, Vigentes, Normas Oficiales Mexicanas CCNNDTIS-SSA3, 4 de diciembre de 2015. Disponible en http://www.gob.mx/salud/documentos/vigentes-normas-oficiales-mexicanas-ccnndtis-ssa3. "Las Normas Oficiales Mexicanas en salud, son normas de carácter técnico para instituciones públicas, sociales y privadas para la prestación de los servicios de atención médica y asistencia social, así como en materia de infraestructura equipamiento y remodelación de todo tipo de establecimientos para los servicios de atención médica, los de formación, capacitación y actualización de los recursos humanos para la salud, y la investigación para la salud que se desarrolla en seres humanos".

${ }^{46}$ CANTORAL DOMÍNGUEZ, K., Derecho a la protección de datos personales de la salud, op. cit., p. 116.

47 ELIZONDO MAYER-SERRA, C., "El derecho a la protección de la Salud", Salud pública de México, núm. 49, núm. 2, 2007, p. 146.

48 WITHENEHAD, M. y DAHLGREN, G., Conceptos y principios de lucha contra las desigualdades sociales en la salud: Desarrollando el máximo potencial en salud parte 1, Oficina Regional de la OMS para Europa, Madrid, 2006. p. $15 . \quad$ Disponible en https://www.mscbs.gob.es/profesionales/saludPublica/prevPromocion/promocion/desigualdadSalud/docs/concepDesi gual.pdf
} 
con lo que tiene y con lo que puede, con insumos limitados para brindar el servicio. Mientras que el sistema privado cuenta con los mejores recursos humanos y materiales, considerado como la primera opción a la que recurren aquellos que tienen amplia posibilidad de pago ${ }^{49}$.

La deficiencia en la calidad de servicio se agudiza frente a la situación generada por los nuevos métodos para alcanzar un óptimo estado de salud, como es el caso de las biopatentes, pues si bien se están generando alternativas médicas que más tarde son patentadas para beneficio en la salud humana, el Estado no está asegurando el cumplimiento máximo de acciones que permitan al individuo acceder a las biopatentes. Sin embargo, en el ordenamiento jurídico mexicano, la universalidad, calidad y equidad parecen homogéneos en términos conceptuales.

Si el derecho a la protección a la salud tiene por objeto el grado de salud más alto del individuo, consecuentemente, el Estado como obligación inherente a él deberá establecer los límites en los ámbitos gubernamentales, sociales y particulares que permitan asegurar los medios posibles para garantizar el derecho a la protección de la salud en su grado máximo.

Una de las principales características de los derechos económicos sociales y culturales - como el de la protección de la salud - es la necesidad de que primen los intereses colectivos por encima de los intereses particulares, a través de ordenamientos jurídicos que tengan como finalidad propiciar condiciones equitativas de vida ${ }^{50}$.

El contexto actual nos refiere a condiciones de desigualdad entre los que pueden acceder a los medicamentos que gozan de biopatentes; $\mathrm{y}$, las personas que debido a sus recursos se ven limitada en su acceso; cómo se puede inferir, el derecho a la protección de la salud va de la mano con las condiciones de igualdad generadas de su aplicación. Condiciones, que - a priori- la concesión de patentes sobre biomateriales derivados del cuerpo humano rompe por la incapacidad del Estado de garantizar a todos el acceso a esos desarrollos científicos. Por ende, deben hacerse cambios a la legislación de patentes sobre biomateriales derivados del cuerpo humano para paliar los efectos adversos en el acceso a los medicamentos.

\section{LINEAMIENTOS Y PRINCIPIOS BIOÉTICOS EN LA INVESTIGACIÓN CIENTÍFICA Y TECNOLÓGICA}

El insumo básico para los biomateriales derivados del cuerpo humano es precisamente la experimentación con células, tejidos o seres humanos ${ }^{51}$. Esto plantea una serie de dilemas éticos que deben ser atendidos garantizando en todo el derecho a la salud. El seguimiento de pautas bioéticas en la investigación debiera ser tomado en cuenta en el momento de acceder a la protección patentaria por considerar que si no se cumplen estaríamos ante una situación contraria a la moral y las buenas costumbres. Este es otro aspecto del derecho a la salud que conviene examinar con respecto a la concesión de las patentes sobre biomateriales derivados del cuerpo humano.

\section{Ley General de Salud}

\footnotetext{
${ }^{49}$ CANTORAL DOMÍNGUEZ, K., Derecho a la protección de datos personales de la salud, op. cit., p.106.

${ }^{50}$ Ibid., p.106.

${ }^{51}$ DADALTO L., "Bioética e integridad científica en la investigación clínica sobre Covid-19”, Bioética, núm. 3, 2020, p. 419. "Las investigaciones centradas en ensayos clínicos, así como desarrollo de biotecnologías tecnologías son consideradas la forma más vulnerable de ejercicio experimental ya que se basan en sujetos de investigación humanos".
} 
Toda patente requiere de un procedimiento previo de investigación científica en condiciones controladas para poder obtenerla. Tan solo el desarrollo de investigación biomédica a partir de procedimientos técnicos —independientemente de ser un producto potencialmente patentable - es una finalidad del derecho a la protección a la salud prevista en el artículo 2, fracción VII de la LGS.

En efecto, la investigación en materia de salud nacional bajo el numeral 96 de la LGS implica el desarrollo de acciones que contribuyan al conocimiento de procesos biológicos en los seres humanos; así como de los vínculos entre las causas de enfermedad, práctica médica y estructura social. Además, deberán estar encaminados a la prevención y control de los problemas de salud prioritarios en la población a través de la producción nacional de insumos para la salud ${ }^{52}$.

Las complejidades derivadas de la investigación biomédica son atendidas en el artículo 41 Bis de la LGS. La fracción I del numeral referido dispone que el sector público, social o privado del sistema de salud deberá contar en cada institución con un comité hospitalario de bioética para el análisis, discusión y apoyo en la toma de decisiones de problemas bioéticos de la práctica clínica, además de la elaboración de lineamientos, guías institucionales para la atención y docencia médica.

En tanto la fracción II del artículo 41 Bis de la LGS se pronuncia por la instauración de comités de ética para los establecimientos de atención médica que realicen investigación en seres humanos, con el objeto de evaluar y dictaminar protocolos de investigación en seres humanos, formulación de recomendaciones y lineamientos éticos.

En ese sentido el artículo 98 de la LGS establece que será responsabilidad de los directores o titulares de las instituciones de salud la conformación de un comité de investigación ${ }^{53}$ y un comité de bioseguridad para determinar y normar el uso de técnicas de ingeniería genética.

Para la conformación de los comités se extendieron dos acuerdos: Acuerdo por el que se emiten las disposiciones generales para la integración y funcionamiento de los comités de ética en investigación y se establecen unidades hospitalarias que deben contar con ellos; y, el Acuerdo por el que se emiten las disposiciones generales para la integración y funcionamiento de los comités hospitalarios de bioética y se establecen las unidades hospitalarias que deben contar con ellos. Las dos disposiciones deben integrarse bajo los criterios establecidos en por la Comisión Nacional de Bioética ${ }^{54}$.

Ambos acuerdos determinan que los comités deben contribuir a la salvaguarda de la dignidad, los derechos, la seguridad, el bienestar de los participantes en la investigación y la

\footnotetext{
${ }^{52}$ Artículo 96 de la LGS y artículo 2 del Reglamento de la Ley General de Salud en Materia para la Investigación para la Salud.

${ }^{53}$ México cuenta con un Manual de Integración y Funcionamiento de los Comités de Investigación elaborado por la Comisión Coordinadora de los Institutos Nacionales de Salud y Hospitales de Alta especialidad, CCINSHAE, aunque las disposiciones del manual son obligatorias para las instituciones de salud, se autoriza su consulta y aplicación para otros centros de investigación, si estos últimos lo consideran pertinente, aunque la ley no los obliga a acatar las disposiciones para los institutos de salud, 15 de enero de 2021. Disponible en http://iner.salud.gob.mx/descargas/normatecainterna/MIcomites/COMITEINVESTIGACION_14102014.pdf

${ }^{54}$ Una de las atribuciones de la Comisión Nacional de Bioética estriba en el establecimiento de políticas públicas para promover la cultura bioética mexicana en los temas vinculados con la salud humana, bajo el cumplimiento de los objetivos del artículo 33 de la LGS, de tal forma que ambos acuerdos para la conformación de comités deben regirse por las disposiciones que determine la Comisión Nacional de Bioética, serán exclusivos para los servicios médicos.
} 
distribución de las cargas de la investigación ${ }^{55}$; finalidades integrales para la protección de los seres humanos, pero que aplican con exclusividad para el sector salud ${ }^{56}$, no siendo previstos otros centros de investigación científica y tecnológica tanto públicos como privados que no brindan directamente atención médica, tal es el caso de institutos académicos de investigación biotecnológica, o instituciones privadas para el desarrollo de biofármacos en México.

\section{Reglamento de la Ley General de Salud en materia de investigación para la salud}

El Reglamento de la Ley General de Salud en materia de investigación para la salud ${ }^{57}$ es complementario del artículo 96 de la LGS que reconoce a la investigación como una de las finalidades del derecho a la protección de la salud. El Reglamento, además de determinar atribuciones de carácter administrativo para la Secretaría de Salud, establece disposiciones comunes en investigaciones de las que el ser humano sea sujeto de estudio; su fundamento estriba en el respeto a la dignidad, la protección de derechos, así como el bienestar del ser humano ${ }^{58}$.

El artículo 14 de este Reglamento establece las bases a las que ha de sujetarse la investigación que se realice en seres humanos. Así las cosas, este numeral dispone que la investigación en seres humanos debe adaptarse a los principios científicos y éticos que justifiquen la investigación ${ }^{59}$; debe contribuir a la solución de problemas de salud; así mismo requiere la experimentación previa realizada en animales en laboratorios o en hechos científicos; y, se deberá realizarse solamente cuando el conocimiento no pueda obtenerse por otro medio.

El mismo numeral determina como prioridad el consentimiento informado de la persona sujeta a la investigación ${ }^{60}$ en vista de asegurar en todo momento la privacidad del individuo sujeto a la investigación ${ }^{61}$; de igual forma, la dirección de las mismas debe producirse en una institución de atención en salud, bajo la supervisión de autoridades sanitarias, con autorización del titular de la institución en atención en salud y con los dictámenes de los Comités de Investigación, de Ética en la Investigación y Bioseguridad.

El Reglamento de la Ley General de Salud en materia de investigación de la salud humana no se limita al establecimiento de normas de índole investigación-sujeto, si no que

\footnotetext{
55 Artículo 5 del Acuerdo por el que se emiten las disposiciones generales para la integración de los Comités de Ética de investigación.

56 "Acuerdo que modifica el diverso por el que se emiten las Disposiciones Generales para la Integración y Funcionamiento de los Comités Hospitalarios de Bioética y se establecen Unidades Hospitalarias que deben contar con ellos", Comisión Nacional de Bioética, publicado en el Diario oficial de la Federación el 06 de junio de 2018. La última modificación realizada al acuerdo, en concreto, es de fecha 06 de junio de 2018 publicada en el Diario Oficial de la Federación respecto a la reducción del tiempo para certificar la inscripción de los comités hospitalarios en la Comisión Nacional de bioética, sin embargo siguen sin ser considerados los centros de investigación científicos y privados que no brindan atención hospitalaria.

57 Reglamento de la Ley General de Salud en Materia de Investigación, publicado en el Diario Oficial de la Federación el 6 de enero de 1987.

${ }^{58}$ Artículo 13 del Reglamento de la Ley General de Salud en Materia de Investigación.

${ }^{59}$ MIRANDA NOVALES, M. y VILLASÍS KEEVER, M., "El protocolo de investigación VIII. La ética de la investigación en seres humanos", Alergia México, núm. 66, 2019, p. 118. De acuerdo con las disposiciones la Ley General de Salud en Materia de Investigación para la Salud, los protocolos de investigación en seres humanos deben incluir una sección donde se mencionen los aspectos éticos de estudio, de forma que sean clasificados según el riesgo de estudio, a saber: investigación sin riesgo, con riesgo mínimo así como riesgo mayor que el mínimo, la selección de dichos criterios corresponde al mismo investigador, al considerarlo bajo criterio personal realizando balance riesgobeneficio.

${ }^{60}$ Artículo 20 del Reglamento de la Ley General de Salud en Materia de Investigación.

${ }^{61}$ Artículo 16 del Reglamento de la Ley General de Salud en Materia de Investigación.
} 
contempla directrices para las investigaciones en comunidades, grupos determinados en la investigación, sujetos vulnerables y productos específicos, tal es el caso de menores de edad, mujeres, comunidades indígenas, además de algunos biomateriales, terapias y diagnósticos. En efecto el Capítulo II del reglamento describe que tratándose de investigaciones en comunidades solo serán admisibles cuando los estudios efectuados en pequeñas escalas no hayan producido resultados concluyentes, además el investigador titular deberá obtener aprobación de las autoridades sanitarias y consentimiento informado. En caso de que las investigaciones comunitarias se realicen en sectores vulnerables como grupos indígenas requiere permiso especial del comité de ética en investigación ${ }^{62}$.

Por otro lado, el Capítulo IV dispone de un apartado para la investigación en mujeres y recién nacidos intitulado: "De la investigación en las mujeres en edad fértil, embarazadas, en trabajo de parto, puerperio, lactancia y recién nacidos; de la utilización de embriones, óbitos y fetos y de la fertilización asistida". La inclusión de pautas para estos sectores poblacionales es indispensable en la investigación biomédica para el desarrollo y ensayos sobre aplicaciones de fármacos, debido a los riesgos inmersos para las mujeres embarazadas o en edad fértil, así como las complicaciones para el feto en caso de un protocolo de intervención mal efectuado ${ }^{63}$.

Por esta razón el reglamento estipula criterios a verificar para las intervenciones de riesgo mayor, consentimiento informado de la mujer en investigación médica, mientras que en el caso de fetos solo podrán ser sujetos de investigación cuando las técnicas y métodos proporcionen seguridad para el producto y la madre.

\section{Noma Oficial Mexicana NOM -012-SSA3-2012, que establece los criterios para la ejecución de proyectos de investigación para la salud en seres humanos}

Los criterios administrativos, éticos y metodológicos para la ejecución de los proyectos de investigación para la salud en seres humanos son regulados por la Norma Oficial Mexicana NOM-012-SSA3-2012, bajo el marco de la LGS y el Reglamento en Materia de investigación en salud. La norma reconoce que la investigación científica, clínica, biomédica, tecnológica, biopsicosocial en el ámbito de la salud es fundamental para promover, proteger y restaurar la salud de los seres humanos. Por ello la investigación debe estar fundamentada en el cuidado ético, el respeto por la integridad física de las personas que participan en la investigación, así como su dignidad humana.

El cumplimiento de los lineamientos de esta norma es indispensable para la autorización de proyectos o protocolos con fines de investigación para el empleo en seres humanos de medicamentos o materiales de los que no se tenga evidencia científica de su eficacia terapéutica y se pretenda su modificación, así como del seguimiento de protocolos, tal y como se desprende del objetivo de la norma oficial ${ }^{64}$.

\footnotetext{
${ }^{62}$ Artículos 28 y 29 del Reglamento de la Ley General de Salud en Materia de Investigación

63 REDONDO CALDERÓN, J., "Experimentación fetal, trasplantes, cosmética y su relación con el aborto provocado", Cuadernos de Bioética, núm. 3, 2012, p. 700. Registros exponen que la investigación biomédica comenzó a utilizar tejido fetal para la producción de vacunas desde el año 1930, esto en vista de experimentar el control de propagación de virus humanos probados en tejido fetal obtenido. A partir de ese suceso este tipo de investigaciones son comunes, tal es el caso de la investigación desarrollada a partir de líneas celulares extraídas de tejido renal fetal humano para cultivar el virus del polio, investigación galardonada con el premio Nobel de Medicina en 1954.

${ }^{64}$ Norma Oficial Mexicana NOM-012-SSA3-2012, que establece los criterios para la ejecución de proyectos de investigación para la salud en seres humanos, objetivos.
} 
La autorización de las investigaciones en seres humanos recae en la Secretaría de Salud, quien deberá verificar que el proyecto y protocolo se conduzca bajo los criterios de respeto a la dignidad humana del sujeto a la investigación, la protección a de sus derechos, de su integridad física y el bienestar de su salud, además de mediar consentimiento informado de los sujetos intervinientes y con principal énfasis en sujetos vulnerables participes en la investigación.

Por otro lado, es necesario la emisión de dictamen por los Comités de Ética, Investigación o Bioseguridad de las instituciones donde se llevará a cabo el proceso, para lo cual el mismo ordenamiento señala disposiciones para la constitución de los comités y su funcionamiento.

No obstante que la NOM -012-SSA3-2012 es una norma de carácter técnico, está basada en el respeto a la dignidad del sujeto a investigar, además de direccionarse bajo criterios éticos; condición fundamental para direccionar el proceso precedente a la concesión patentaría de biomateriales derivados del cuerpo.

Sin embargo aunque son normas obligatorias, el ámbito de aplicación es de cumplimiento exclusivo a los profesionales de la salud, instituciones o establecimientos para la atención médica en los sectores público, social y privado, consecuentemente queda desprotegido el sector privado dedicado a la investigación y desarrollo de biofármacos tal es el caso de consorcios farmacéuticos, además de los centros académicos o universidades que realicen estas tareas, que como abordábamos en el capítulo primero son productoras por excelencia de patentes derivadas del cuerpo humano.

\section{Norma Oficial Mexicana NOM-257-SSA1-2014 en materia de medicamentos biotecnológicos}

La concesión de patentes sobre medicamentos es una práctica vigente sobre todo en el proceso de elaboración de fármacos y recientemente en aquellos desarrollados a partir de biomateriales del cuerpo humano o sus derivados. El monopolio patentario se justifica para recuperar las cuantiosas inversiones de recursos económicos en la investigación sobre salud humana. Ahora bien, la creación de fármacos derivados de biomateriales humanos requiere de normas especializadas que regulen el proceso de investigación y ejecución del mismo, además de la autorización sanitaria del producto final, por ello las Normas Oficiales Mexicanas se pronunciaron por la creación de la NOM-257 en Materia de Medicamentos biotecnológicos.

Los objetivos de esta norma oficial radican en establecer las directrices generales de operación para la evaluación de la información técnica y científica presentada durante el proceso de solicitud de registro de medicamentos biotecnológicos ${ }^{65}$, el establecimiento de criterios por los cuales la Secretaría de Salud lleva a cabo el proceso de regulación del medicamento, el proceso de autorización de protocolo de ensayos clínicos de medicamentos biotecnológicos y las especificaciones que deben cumplir los medicamentos biotecnológicos ${ }^{66}$.

El campo de aplicación de la norma es el territorio nacional para los solicitantes de registro sanitario y prorroga de los medicamentos biotecnológicos, tal y como lo refiere el punto 11 de la NOM en comento ${ }^{67}$, es una norma no armonizada con otras disposiciones legales mexicanas. A pesar de que remite para casos excepcionales a las normas oficiales mexicanas relativas al expediente clínico y de instalación y operación de la farmacopea, la esencia de la

\footnotetext{
${ }^{65}$ Epígrafe 1 de la Norma Oficial Mexicana NOM-257-SSA1-2014 en materia de medicamentos biotecnológicos.

${ }^{66}$ Epígrafes 1.1 al 1.5. de la Norma Oficial Mexicana NOM-257-SSA1-2014 en materia de medicamentos.

${ }^{67}$ Epígrafe 11 de la Norma Oficial Mexicana NOM-257-SSA1-2014 en materia de medicamentos.
} 
NOM-257 está enfocada en la calidad del fármaco biotecnológico y sus variantes. Con lo que se dejan de lado los criterios bióticos que deben regir en el proceso de elaboración de medicamentos sobre todo de aquellos en los que la materia prima sean biomateriales derivados del cuerpo humano.

Hasta este punto, el análisis de la legislación mexicana implicada en el proceso de elaboración, concesión y efectos posteriores de las patentes derivadas del cuerpo humano, ha permitido observar que la LPI es interpretativa respecto a los criterios tomados para la concesión de biopatentes.

Por otro lado, en el proceso precedente a la solicitud de derechos patentarios, específicamente en los ordenamientos derivados de la Ley General de Salud, evidencian un engranaje integral de la investigación en materia de salud en seres humanos, contemplan protección de algunos de los derechos humanos, en particular el derecho a la salud.

Sin embargo, aplica con exclusividad al sector salud, por lo tanto para las empresas privadas, centros de investigación tecnológica y demás que realicen investigaciones con biomaterial derivado del cuerpo no son de carácter coactivo en la elaboración de protocolos de investigación, comités de bioética, bioseguridad e investigación, solo por mencionar algunas. Así pues, con el objeto ilustrar la necesidad de una legislación nacional que medie los derechos de propiedad industrial con los derechos humanos y principios bioéticos se abordaran algunas solicitudes de biopatentes radicadas en el territorio mexicano.

\section{ANÁLISIS DE LAS SOLICITUDES DE PATENTES SOBRE BIOMATERIALES DERIVADOS DEL CUERPO HUMANO PRESENTADAS ANTE EL INSTITUTO MEXICANO DE LA PROPIEDAD INDUSTRIAL}

En este último apartado analizaremos solicitudes de patentes que reivindican invenciones sobre biomateriales derivados del cuerpo humano presentadas ante el IMPI. Las mismas serán estudiadas desde la perspectiva de los derechos humanos, en particular del derecho a la salud. Las solicitudes planteadas en esta sección forman parte del Catálogo de Patentes de Invención Solicitadas, publicadas en el Sistema de Información de la Gaceta de la Propiedad Industrial del IMPI ${ }^{68}$. Han sido seleccionadas únicamente aquellas que representan el núcleo del problema de investigación ${ }^{69}$.

\section{Solicitudes MX/A/2007/003885 y PA/A/2006/008360 del Centro de Investigaciones Avanzadas}

La primera solicitud de biopatente proviene del Centro de Investigación y de Estudios Avanzados del Instituto Politécnico Nacional, (CINVESTAV), radicada bajo el número MX/A/2007/003865 intitulada "Métodos para el diagnóstico temprano de infecciones virales y de enfermedades respiratorias o de predisposición de un individuo a desordenes proliferativos o hiperplasia”. La novedad de invención consiste en la creación de un método para identificar la

\footnotetext{
${ }^{68}$ Boletín disponible través del Sistema de Información de Portal Oficial de la Gaceta de la Propiedad Industrial, SIGA

${ }^{69}$ Es importante mencionar que el acceso a los catálogos de solicitudes patentarias actuales es reservado en México. Es posible acceder a ellos previa liberación paulatina del IMPI a través del Sistema de Información de la Gaceta de la propiedad Industrial.
} 
predisposición de un sujeto a un desorden proliferativo o una hiperplasia ${ }^{70}$ y yn método para el diagnóstico temprano de una infección viral o una enfermedad inflamatoria; comprende el paso del análisis del nivel de expresión de un gen o la actividad de un correspondiente producto de los genes en una muestra de tejido o células humanas. La patente fue concedida el 17 de septiembre de $2015^{71}$.

El CINVESTAV también presentó la solicitud de patente PA-A/2006/008360 que comparte similitud con la patente anterior, ya que en ambas producciones fue indispensable la recolección de biomateriales derivados del cuerpo humano ${ }^{72}$. La patente radicada como "Cisteínas proteinasas útiles para el diagnóstico de la infección trichomonas vaginalis" reside en él, la elaboración de un método para diagnosticar la infección Trichomonas vaginalis; este diseño requirió una toma de fluido corporal humano con la finalidad de aislar al patógeno trichomonas vaginalis y con ello diseñar anticuerpos auxiliares a la identificación de éste patógeno en pacientes que se presuma padezcan la enfermedad. La patente fue concedida el 25 de mayo de $2015^{73}$.

Así las cosas, si se examinan ambas solicitudes patentarias con base a los criterios del artículo 16 facción II de la LPI, la concesión se basa en el aislamiento de elementos químicos tanto del tejido como del fluido corporal, a través de un procedimiento controlado que media en el desarrollo del producto final, lo cual se aleja de las excepciones de patentabilidad sobre materia viva en su estado puro. Sin embargo, a pesar de cumplir con el criterio de aislamiento de elementos químicos de biomateriales derivados del cuerpo humano, hay una ausencia normativa reglamentaria no contemplada por la legislación actual para el proceso previo a la solicitud patentaría.

En efecto, como hemos observado en la revisión de ordenamientos jurídicos mexicanos, el desarrollo de la investigación biomédica carece de legislación coactiva especializada para el manejo de toma de biomateriales, el resguardo y el consentimiento de los mismos ${ }^{74}$.

Por otro lado, tampoco se habla de la necesidad de fijar códigos bioéticos, comités de investigación o bioseguridad para los centros de investigación ajenos al sector salud, a diferencia de las instituciones médicas regidas por la LGS quienes son sometidas al cumplimiento de ordenamientos, reglamentos y normas oficiales mexicanas para el desarrollo de investigación en salud.

\footnotetext{
${ }^{70}$ Diccionario Médico, enciclopedia médica y terminología médica, s.v. HIPERPLASIA, 23 de agosto de 2020. Disponible en http://www.diccionariomedico.net/diccionario-terminos/7615-hiperplasia. La Hiperplasia es el desarrollo excesivo de un tejido u órgano, producido por una proliferación celular exagerada. A nivel histológico, en las hiperplasias se aprecia un aumento en la cantidad de células que forman un órgano o tejido.

71 "Gaceta de la Propiedad Industrial del IMPI”, diciembre de 2020, p. 32.

72 UNIVERSIDAD NACIONAL AUTÓNOMA DE MÉXICO, Catálogo de patentes de Invención Solicitadas: Publicadas en el Sistema de Información de la Gaceta de la Propiedad Industrial del Instituto Mexicano de la Propiedad Industrial 1991-2009, op. cit., p. 940.

73 “Gaceta de la Propiedad Industrial del IMPI”, diciembre de 2020, p. 55.

74 CERÓN, R., "México, cuarto país con bancos de cordón umbilical”, El Universal, 2007, 23 de agosto de 2020. Disponible en http://archivo.eluniversal.com.mx/cultura/51455.html. "México es uno de los países que cuenta con establecimientos privados para la crio preservación de células y tejidos, se calcula que hay cerca de 10 empresas privadas titulares con sus respectivas franquicias operando en el territorio mexicano".
}

BENITEZ ARVIZU, G., "Biobancos de Células Troncales para terapia celular, una realidad en México", Revista Médica del Instituto Mexicano del Seguro Social. núm.3, 2014, p. 247. "En México, los biobancos que almacenan muestras biológicas son muy disímiles en cuanto a sus objetivos, diseño, composición y regulación, si bien comparten algunas características al apegarse a regulación internacional, en México no existe una legislación clara y seria que sistematice la tenencia y el manejo de muestras biológicas". 
Ahora bien, una concesión patentaría sobre un método de diagnóstico médico en un primer punto sería descartada bajo el numeral 19 fracción VII de la LPI, que refiere que no serán consideradas invenciones los métodos de tratamiento quirúrgico, terapéutico o de diagnóstico aplicables al cuerpo humano esto debido a que atentaría con el derecho humano a la igualdad y no discriminación al restringir el acceso a la población que pueda beneficiarse con métodos o terapias desarrolladas como invenciones.

No obstante, la solicitud MX/A/2007/003865 se presenta como una patente para el desarrollo de un método el diagnóstico temprano, hecho que condiciona la previa existencia de un método convencional lo que permite flexibilidad en la disposición del artículo 19 del a LPI. Así pues la autorización de la patente eleva los costos de un diagnóstico temprano, consecuentemente habría un desequilibrio entre el derecho humano a la igualdad de acceso a la salud frente a los derechos de propiedad industrial, con ello se acentuaría una situación de discriminación de los sectores de bajo poder adquisitivo que quieran acceder a un diagnóstico temprano.

\section{Solicitud NL/A/2006/000035 del Instituto Potosino de Ciencia y Tecnología}

De centros públicos de investigación destaca la patente NL/A/2006/000035, titulada "Plásmido PLR para la expresión de proteínas recombinantes en bacterias del género bifidobacterium". Esta patente estriba en el desarrollo de un vector como vehículo conductor para el género bifidubacterium; este vector permite exportar proteínas hacia un medio extracelular. La proteína IL-10 utilizada en el desarrollo del plásmido es una proteína que ayuda al tratamiento de enfermedades inflamatorias como colitis ulcerosa, mieloma múltiple, melanoma, linfoma no-Hodking's, enfermedad de crhon, artritis reumatoide, esclerosis múltiple, lupus, psoriasis, entre otras enfermedades descritas en el resumen de la patente ${ }^{75}$. La solicitud fue declarada abandonada por haber incumplido con un requerimiento en el examen de fondo ${ }^{76}$, no obstante es interesante analizar las consideraciones de la solicitud desde el punto de vista de los derechos humanos.

Aunque la novedad consiste en la creación de un medio conductor de proteínas o vector que ayuda al tratamiento de las enfermedades descritas, este plásmido está desarrollado a partir de un gen que codifica la interleucina-10 humana, obtenida de un proceso previo de aislamiento de elementos químicos tomados del cuerpo humano.

Como se puede observar de la descripción de la patente, es evidente el beneficio de la invención reivindicada en el tratamiento de enfermedades inflamatorias. Sin embargo, el beneficio en la salud humana no podría justificar la toma de biomaterial sin consentimiento informado de la persona intervenida, debido a que constituiría una violación al derecho humano a la integridad personal.

En este caso, no sabremos si en el proceso de investigación, elaboración y solicitud de la patente NL/A/2006/000035 se tomaron las medidas adecuadas para la protección de los derechos humanos comentados, pues — como hemos observado- los lineamientos bioéticos no son contemplados en la patentabilidad de biomateriales derivados del cuerpo humano.

\footnotetext{
75 UNIVERSIDAD NACIONAL AUTÓNOMA DE MÉXICO, Catálogo de patentes de Invención Solicitadas: Publicadas en el Sistema de Información de la Gaceta de la Propiedad Industrial del Instituto Mexicano de la Propiedad Industrial 1991-2009, op. cit., p. 1116.

76 "Gaceta de la Propiedad Industrial del IMPI", marzo de 2017 p. 46
} 


\section{Solicitudes MX/A/2008/012111 y PA/A/2006/007636 del Instituto Mexicano del Seguro Social}

Por otro lado, no podemos dejar de mencionar las patentes solicitadas por instituciones nacionales de salud. Del Instituto Mexicano del Seguro Social se distingue la patente MX/A/2008/012111, denominada "Método y equipo para la detección rápida de Mycobacterium tuberculosis en muestras de líquido cefalorraquídeo". ${ }^{77}$ Esta patente fue concedida el 30 de marzo de $2012^{78}$. Como se desprende del título, la invención consiste en el desarrollo de un método para la detección rápida de una infección por Mycobacterium tuberculosis; la efectividad del método da por hecho que ha sido probado sobre líquido cefalorraquídeo tal y como se desprende del título de la invención. Dicha patente sería inexistente sin la obtención, manipulación e investigación del biomaterial expuesto.

Si bien las instituciones derivadas del sistema de salud establecen lineamientos más integrales para la investigación en seres humanos, se debe dar seguimiento minucioso al uso de datos personales obtenidos de las muestras biológicas, con el fin de producir la consolidación del respeto por la protección de datos personales. La protección de los derechos humanos interactuantes en la investigación biomédica para el desarrollo de patentes debe ser una red de acciones encaminadas a la protección de la persona en todos sus sentidos.

El propio IMSS solicitó una patente sobre un método para la detección del cáncer de cérvix PA/A/2006/007636. El proceso inventivo sobre el que se basa la invención refiere que para el desarrollo del método fueron obtenidas - por medio de procesos biotecnológicos - las proteína catepsina f, metaloproteinasa 11 y 12 de una muestra de tejido canceroso; proteínas asociadas al cáncer, por lo tanto resultan funcionales para la detección rápida del cáncer de cérvix o precursor del mismo en un individuo ${ }^{79}$. La patente fue concedida el 23 de abril de $2012^{80}$.

El desarrollo de métodos de diagnóstico médico como los expuestos anteriormente forman parte de una de las acciones constitutivas del derecho a la protección a la salud, por lo tanto como derecho humano lleva implícito la garantía de cumplimiento inmediato ${ }^{81}$; en caso de que el sistema jurídico no ofreciera a los titulares del derecho a la protección a la salud su pronta materialización incurriría a una vulneración del derecho humano en comento. Por esta razón la LPI prohíbe extender derechos patentarios sobre métodos de diagnóstico ya que obstaculizaría la materialización inmediata de la protección a la salud y la segregación de grupos vulnerables, aunque en la práctica como vemos la solicitud de métodos de diagnóstico temprano ofrezca una válvula de escape para su concesión.

\section{CONCLUSIONES}

De lo anteriormente expuesto podemos concluir:

Las legislaciones de patentes, vía una alambicada argumentación, han abierto la puerta a la patentabilidad de biomateriales derivados del cuerpo humano. El derecho europeo, en

\footnotetext{
77 UNIVERSIDAD NACIONAL AUTÓNOMA DE MÉXICO, Catálogo de patentes de Invención Solicitadas..., op. cit., p. 1193.

78 “Gaceta de la Propiedad Industrial del IMPI", abril de 2012, p. 13.

${ }^{79}$ UNIVERSIDAD NACIONAL AUTÓNOMA DE MÉXICO, Catálogo de patentes de Invención Solicitadas..., op. cit., p. 1200.

80 “Gaceta de la Propiedad Industrial del IMPI", abril de 2012, p. 208.

${ }^{81}$ CANTORAL DOMÍNGUEZ, K., Derecho a la protección de datos personales de la salud, op. cit., p. 116.
} 
particular la Directiva 98/44 sobre invenciones biotecnológicas aportan un modelo a seguir en México para una adecuada aplicación de la legislación de patentes en materia de biomateriales derivados del cuerpo humano. Demostramos que el CPE y la Directiva 98/44 son compatibles con la regulación de la LPI. Podemos fácilmente concluir que los criterios interpretativos de la Oficina Europea de Patentes y los criterios jurisprudenciales del Tribunal de Justicia de la Unión Europea pueden servir de modelo para la aplicación de la legislación de patentes mexicana.

Por otra parte, tratamos de hacer un balance con el derecho a la salud. Este lo abordamos desde dos perspectivas. La primera como derecho a la protección de la salud indisolublemente ligado al acceso a los servicios de salud. Las patentes sobre biomateriales derivados del cuerpo humano, si bien pueden acelerar el desarrollo de medicamentos pueden impedir el acceso a esos productos a la población. Hacemos hincapié en la necesidad de flexibilizar el derecho de patentes para un contexto como el de México, donde el acceso a los servicios de salud dista mucho de los niveles que tiene en el continente europeo. Porque, si bien es cierto que las patentes son un mecanismo de fomento a la investigación, no podemos perder de vista que el encarecimiento de los medicamentos que trae como consecuencia pueden ocasionar un problema de salud pública.

El otro aspecto del derecho a la salud que analizamos es el de las pautas éticas en la investigación biomédica. La LGS establece la obligación de comités de investigación bioética. También analizamos el Reglamento de la Ley General de Salud en Materia de Investigación para la Salud y dos normas oficiales mexicanas que regulan las cuestiones bioéticas de la investigación en seres humanos y los medicamentos biotecnológicos. Hacemos notar que existe un área de mejora para que esta regulación esté plenamente operativa de manera coherente. Asimismo, debemos hacer notar que es necesario elevar el nivel de exigencia de cumplimiento de los parámetros éticos en la investigación sobre biomateriales derivados del cuerpo humano, con objeto de evitar que se concedan patentes basadas en procesos de investigación que atenten contra la dignidad humana.

En último lugar, analizamos varias solicitudes de patentes sobre biomateriales derivados del cuerpo humano de instituciones públicas de salud y centros públicos de investigación en México. Nuestro principal hallazgo es que en las propias solicitudes de patentes no se demuestra el cumplimiento de los parámetros éticos que disponen las leyes, reglamentos y normas oficiales analizadas. Por otra parte, en la vertiente positiva, podemos constatar que las instituciones públicas de salud y de investigación tienen un formidable instrumento en las patentes como incentivo para realizar investigación.

\section{REFERENCIAS BIBLIOGRÁFICAS}

- ARCUDiA HERNÁNDEZ, C., "Patentes sobre invenciones biotecnológicas: criterios legales y jurisprudenciales europeos y su aplicabilidad en el derecho mexicano", Revista Entreciencias, Diálogos en la sociedad del conocimiento, núm. 7, 2015, pp.167-182.

- BENITEZ ARVIZU, G., "Biobancos de Células Troncales para terapia celular, una realidad en México", Revista Médica del Instituto Mexicano del Seguro Social, núm. 3, 2014, pp. 244-247.

- BOYLE, J., "Las ideas cercadas: el Confinamiento y la Desaparición del Dominio Público" en VILLARREAL PADILLA, J., ¿Un mundo patentado? La privatización de la vida y el conocimiento, Bellas Artes, El Salvador, 2005. 
- CANTORAL DOMÍNGUEZ, K., Derecho a la protección de datos personales de la salud, Novum, México, 2012.

- CARBONELl, J. y CARBONELL, M., El derecho a la salud, una propuesta para México, UNAM, México, 2013. Disponible https://archivos.juridicas.unam.mx/www/bjv/libros/7/3274/3.pdf

- CERÓN, R., "México, cuarto país con bancos de cordón umbilical”, El Universal, 2007, 23 de agosto de 2020. Disponible en http://archivo.eluniversal.com.mx/cultura/51455.html

- COMITÉ DE DERECHOS ECONÓMICOS, SOCIALES Y CULTURALES DE LAS NACIONES UNIDAS, Evaluación de la Obligación de Adoptar Medidas hasta el "Máximo de los Recursos de que Disponga" de Conformidad con un Protocolo Facultativo del Pacto, E/C.12/2007/1, 21 de septiembre de 2007. Disponible en http://undocs.org/sp/E/C.12/2007/1

- Convenio de Múnich sobre Concesión de Patentes Europeas, de 5 de octubre de 1973.

- DADALTO, L., "Bioética e integridad científica en la investigación clínica sobre Covid19”, Bioética, núm. 3, 2020, pp. 418-425.

- DARIO BERGEL, S., "El vínculo de la genética con los derechos humanos", en PENCHASZADEH, V. B., Genética y derechos humanos, encuentros y desencuentros, Paidós, Buenos Aires, 2012.

- Diccionario Médico, enciclopedia médica y terminología médica, s.v. HIPERPLASIA, 23 de agosto de 2020. Disponible en http://www.diccionariomedico.net/diccionarioterminos/7615-hiperplasia

- DieTERLEN, P., "La Protección a la salud como un mínimo decente y como un derecho básico”, en Justicia distributiva y salud, Tópicos, México, 2015.

- Directiva 98/44/CE del Parlamento Europeo y del Consejo, 6 de julio de 1998, relativa a la Protección Jurídica de las Invenciones Biotecnológicas.

- ELIZONDO MAYER-SERRA, C., "El derecho a la protección de la Salud", Salud pública de México, núm. 49, núm. 2, 2007, pp. 144-155.

- IZQuierdo TOlosA, A. y PÉREZ ZAZUETA, G., La Biotecnología en México, Biotecnología, México, Secretaría de Economía, 2014.

- Ley de la Propiedad Industrial, publicada en el Diario Oficial de la Federación el 27 junio de 1991.

- Ley General de Salud, publicada en el Diario Oficial de la Federación el 7 de febrero de 1984.

- MIRANDA NOVALES, M. y VILLASÍS KEEVER, M., "El protocolo de investigación VIII. La ética de la investigación en seres humanos", Alergia México, núm. 66, 2019, pp. 115-122.

- Norma Oficial Mexicana, NOM -012-SSA3-2012, publicada en el Diario Oficial de la Federación el 4 de enero de 2013.

- Norma Oficial Mexicana, NOM-257-SSA1-2014, publicada en el Diario Oficial de la Federación el 11 de diciembre de 2014. 
- Norma Oficial Mexicana, NOM-257-SSA1-2014, publicada en el Diario Oficial de la Federación el 11 de diciembre de 2014.

- OFICINA DEL ALTO COMISIONADO DE LAS NACIONES UNIDAS PARA LOS DERECHOS HUMANOS, El derecho a la Salud, Folleto informativo, núm. 31, Naciones Unidas, Ginebra, 2008. Disponible en http://www.ohchr.org/Documents/Publications/Factsheet31sp.pdf

- ORGANIZACIÓN MUNDIAL DE LA SALUD, ¿Cómo define la OMS a la salud?. Disponible en http://www.who.int/suggestions/faq/es/

- ORGANIZACIÓN MUNDIAL DE LA SALUD, Salud y derechos humanos: Datos y cifras. Disponible en http://www.who.int/mediacentre/factsheets/fs323/es/

- ORGANIZACIÓN PARA LA COOPERACIÓN Y EL DESARROLLO ECONÓMICOS (OCDE), Estudios Ejecutivos de la OCDE sobre los Sistemas de Salud: México, Resumen Ejecutivo, Diagnóstico y Recomendaciones, OECD, 2016. Disponible en http://www.inep.org/images/2017/2017-pdf/2016-OECD-Reviews-of-Health-SystemsMexico.pdf

- PÉREZ REYES, C., Glosario de Términos Básicos de Derechos Humanos, CDHDF, México, 2005.

- RAMÍREZ LÓPEZ, A., Derecho a la salud, UNAM, México, 2003.

- RANGEL MEDINA, D, Derecho Intelectual, México, 1998. Disponible en https://archivos.juridicas.unam.mx/www/bjv/libros/4/1912/5.pdf

- RANGEL ORTÍZ, H., "Las invenciones que involucran materia viva en el Derecho mexicano", Estudios de derecho de autor y propiedad industrial homenaje al Licenciado José Luis Caballero Cárdenas, OMPI, México, 2015, p. 281.

- REDONDO CALDERÓN, J., "Experimentación fetal, trasplantes, cosmética y su relación con el aborto provocado", Cuadernos de Bioética, núm. 3, 2012, pp. 695-725.

- Reglamento de la Ley General de Salud en materia de Investigación, publicado en el Diario Oficial de la Federación el 6 de enero de 1987

- SECRETARÍA DE SALUD, Vigentes, Normas Oficiales Mexicanas CCNNDTIS-SSA3, 4 de diciembre de 2015. Disponible en http://www.gob.mx/salud/documentos/vigentesnormas-oficiales-mexicanas-ccnndtis-ssa3

- Suprema Corte de Justicia de la Nación, SCJN, del Juicio de Amparo en Revisión 378/2014, foja 116.

- TRENS FLORES, E. y MORALES LECHUGA, V., "A propósito de la patente de los genes”, Revista Facultad de Medicina UNAM, núm. 6, 2003, pp. 226-228.

- UNIVERSIDAD NACIONAL AUTÓNOMA DE MÉXICO, Catálogo de patentes de Invención Solicitadas: Publicadas en el Sistema de Información de la Gaceta de la Propiedad Industrial del Instituto Mexicano de la Propiedad Industrial 1991-2009. Disponible en http://dgei.unam.mx/patentes/catalogo_general.pdf

- Withenehad, M. y DAHLGREN, G., Conceptos y principios de lucha contra las desigualdades sociales en la salud: Desarrollando el máximo potencial en salud parte 1, Oficina Regional de la OMS para Europa, Madrid, 2006. Disponible en 
https://www.mscbs.gob.es/profesionales/saludPublica/prevPromocion/promocion/desiguald adSalud/docs/concepDesigual.pdf

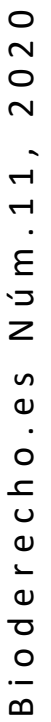

